\title{
RESEARCH
}

\section{Dihydrotestosterone induces pro-angiogenic factors and assists homing of MSC into the cardiac tissue}

\author{
Mirel-Adrian Popa1*, Maria-Cristina Mihai1*, Alina Constantin', Viorel Șuică1, Cătălin Țucureanu², \\ Raluca Costache³, Felicia Antohe1, Raghvendra K Dubey4,5 and Maya Simionescu1 \\ 'Institute of Cellular Biology and Pathology 'Nicolae Simionescu' of the Romanian Academy, Bucharest, Romania \\ 2Infection and Immunity Laboratory, National Institute for Research and Development in Microbiology and Immunology 'I. Cantacuzino', \\ Bucharest, Romania \\ 3Department of Obstetrics and Gynecology, Clinical Hospital 'Dr. Ioan Cantacuzino', Bucharest, Romania \\ ${ }^{4}$ Department for Reproductive Endocrinology, University Hospital Zurich, Schlieren, Switzerland \\ 5Zurich Center for Integrative Human Physiology (ZIHP), University of Zurich, Zurich, Switzerland \\ Correspondence should be addressed to M A Popa or M-C Mihai: mirel.popa@icbp.ro or cristina.corotchi@icbp.ro \\ *(M-A Popa and M-C Mihai contributed equally to this work)
}

\begin{abstract}
The use of mesenchymal stem cells (MSC) as a therapeutic tool in cardiovascular diseases is promising. Since androgens exert some beneficial actions on the cardiovascular system, we tested our hypothesis that this hormone could promote MSC-mediated repair processes, also. Cultured MSCs isolated from Wharton's jelly were exposed to $30 \mathrm{nM}$ dihydrotestosterone (DHT) for 1 or 4 days and the effects of the hormone on their growth/migration/adhesion and the underlying mechanisms were assessed. Results were obtained by real-time cell impedance measurements, and DNA quantification showed that DHT increased MSC proliferation by $\sim 30 \%$. As determined by $\mathrm{xCELLigence}$ system, DHT augmented ( 2 folds) the migration of MSC toward cardiac tissue slices (at $12 \mathrm{~h}$ ), and this effect was blocked by flutamide, an androgen receptor (AR) antagonist. Exposure of cells to DHT, upregulated the gene and protein expression of $A R, E M M P R I N$ and MMP-9 and downregulated the expression of MMP-2. DHT significantly induced the release of nitric oxide by MSC ( $\geq 2$-fold) and flutamide blocked this effect. When MSCs were co-cultured with cardiac slices, immunohistochemical analysis and qRT-PCR showed that the integration of DHT-stimulated MSC was significantly higher than that of in controls. In conclusion, our findings provide the first evidence that DHT promotes MSC growth, migration and integration into the cardiac slices. The modulating effects of DHT were associated with upregulation of ARs and of key molecules known to promote tissue remodeling and angiogenesis. Our findings suggest that priming of MSC with DHT may potentially increase their capability to regenerate cardiac tissue; in vivo studies are needed to confirm our in vitro findings.
\end{abstract}

Journal of Molecular Endocrinology (2018) 60, 1-15 


\section{Introduction}

Heart disease is the leading cause of mortality and morbidity worldwide (Karantalis \& Hare 2015). Although, multiple therapeutic, medical and surgical approaches have been developed to delay and treat the progression of the disease process, beside heart transplantation, a therapeutic approach for permanent cure of the damaged heart following myocardial infarction or heart failure remains elusive (Davis et al. 2000, Karantalis \& Hare 2015). Recent progress in stem cell research for tissue regeneration highlights the potential use of pluripotent adult stem/precursor cells to reconstruct or regenerate various tissues without comprising ethical issues (Nesselmann et al. 2008, Karantalis \& Hare 2015, Singh et al. 2016). In this context, multipotent mesenchymal stem cells (MSC) that are capable of converting into different cell types have gained attention to serve as a therapeutic tool for permanently repairing/regenerating the damaged heart tissue. The MSCs are of mesodermal origin and can differentiate into various cell types (endothelial cells, osteoblasts, chondrocyte, adipocyte, myocyte) when exposed to specific growth factors, signaling molecules and transcription factors (Karantalis \& Hare 2015). More importantly, they can be cultured and primed for delivery in an in vitro setting (Karantalis \& Hare 2015). MSC can be isolated from multiple sources (adipose tissue, placenta, gut, lung, liver, amniotic fluid, dental pulp, periodontal pulp, heart). Taken together, the multiple tissue sources and pluripotent nature of MSC, together with the ease of in vitro expansion, makes them an attractive therapeutic tool for treating heart damage.

The last decade has seen multiple animal as well as clinical trials assessing the therapeutic potential of MSC in repairing cardiac damage and function (Nesselmann et al. 2008, Singh et al. 2016). Although many (not all) studies have established the potential improvement in neovascularization, scar reduction and functional recovery, a major pitfall of MSC therapy is the low retention of transplanted cells, i.e. $0.44 \%$ of transplanted MSC resided in myocardium after 4 days (Toma et al. 2002, Müller-Ehmsen et al. 2006). This has led to a call for further optimization of MSC therapy by identifying molecules that could be used to prime/treat MSC or the recipient(s) to increase MSC homing-in and retention (Ray \& Novotny 2008). Since androgens have been shown to stimulate growth and influence cardiovascular cell's activity (Liu et al. 2003, Ikeda et al. 2005), together with the fact that they promote growth and angiogenesis in progenitor endothelial cells and stem cells (Cai et al. 2016), we hypothesize that androgen(s) may also facilitate MSC growth and homing-in in the heart tissue. Our hypothesis together with the fact that stem cell therapy is likely to be used in ageing men with low androgen levels (Gupta et al. 2008) may be of clinical relevance as pretreatment of recipients with androgen(s) may facilitate higher retention of transplanted cells.

To test our hypothesis, in this study, we assessed the effects of DHT, which is an androgen analog that is not converted to estrogen and selectively induces its biological effects via ARs, on the growth, migration and integration of MSC into cardiac slices. Using MSC co-cultured with cardiac tissue slices, we assessed the modulator effects of DHT on key actors (MMPs, VEGF-1, NO) of the pathways actively involved in tissue repair process such as proteolysis of fibrotic/ scar tissue to promote MSC adhesion, angiogenesis/ growth (proliferation, migration) and tissue repair. We report here that stimulation of MSC with DHT induces increased cell proliferation, migration and chemotaxis potentially via mechanism(s) involving ARs and MMPs, enhances cell migration toward the cardiac tissue slices and generate augmented secretion of angiogenin, VEGF and $\mathrm{NO}$, factors involved in the invasion and integration of cells into ischemic tissues.

\section{Materials and methods}

\section{Cell culture}

Human MSCs were isolated from Wharton's jelly (WJ) and characterized as previously described (Corotchi et al. 2013). All the procedures were approved by the Ethical Committee of the Institute of Cellular Biology and Pathology 'Nicolae Simionescu'. Morphological characterization of the cells was done using an inverted microscope (Nikon Eclipse TE300, Nikon) and a digital camera system for imaging (Nikon Digital Net Camera DN100, Nikon).

\section{Adherence and proliferation assays}

WJ-derived MSCs were plated at a density of $25 \times 10^{4}$ cells per $75 \mathrm{~cm}^{2}$ flasks in the presence of 1,30 and $100 \mathrm{nM}$ DHT. The adherence and proliferation of DHT-treated MSC was determined in real-time using the xCELLigence and E-plate 16-View system (Roche). Briefly, after the cells were seeded onto the E-plate, various concentrations of DHT (AppliChem GmbH, 
Darmstadt, Germany) were added at time 0 and maintained for the entire period of the experiment. Automatically, the impedance values of each well were monitored by the xCELLigence system for $160 \mathrm{~h}$. Based on cell impedance, the software monitored the cell index (CI) value, which is directly correlated with the cell number per well. We have used the RTCA DP 1.2.100 Software that allows to select different display possibilities, and we choose a linear graphic (which skips the lag phase) for a representative evolution in time of the treatment-dependent cell proliferation rate. The experiments were done three times in duplicate.

To verify the results obtained from the proliferation assay and get an accurate measure of cell number, we applied for DNA determination using the CyQuant Cell Proliferation Kit from Thermo Fisher Scientific, following the manufacturer instructions.

\section{Real-time PCR technique}

The mRNA gene expression for AR, EMMPRIN, MMP-2, $M M P-9$ and GAPDH was assessed by real-time PCR system (Applied Biosystems 7900HT, Life Technologies). Briefly, after $96 \mathrm{~h}$ in culture of DHT-treated and non-treated MSC, total RNA was extracted using PureLink RNA Mini Kit (Life Technologies). The RNA concentration was measured with a NanoDrop ND-1000 spectrophotometer (Thermo Fisher Scientific). The cDNA synthesis was done using $1 \mu \mathrm{g}$ of total RNA. The cDNA samples were amplified (in triplicates) for 40 cycles $\left(95^{\circ} \mathrm{C}\right.$ for $2 \mathrm{~min}, 95^{\circ} \mathrm{C}$ for $5 \mathrm{~s}, 60^{\circ} \mathrm{C}$ for $10 \mathrm{~s}, 72^{\circ} \mathrm{C}$ for $15 \mathrm{~s}$ and a dissociation cycle at $95^{\circ} \mathrm{C}$ for $15 \mathrm{~s}$ and $60^{\circ} \mathrm{C}$ for $15 \mathrm{~s}$.) with specific oligonucleotide primers for AR, EMMPRIN, MMP-2, MMP-9 and GAPDH, as endogenous control. The primers used are shown in Table 1. As negative controls, unstimulated cells were employed. Data were expressed as means of fold expression (relative quantification) values and positive $( \pm)$ S.E.M. of each gene in comparison with non-treated MSC and normalized to an arbitrary value of 1 . Significant $P$ values were calculated from $\Delta \Delta \mathrm{Ct}$ values with analysis of variance (ANOVA) tests.

\section{Western blot assay}

MSCs were cultured $(96 \mathrm{~h})$ in the absence or presence of DHT (30nM). After two washes in PBS, cell lysates were prepared using Pierce Lysis Buffer, Halt Protease Inhibitor Single-Use Cocktail (Thermo Fisher Scientific) and a 10-min centrifugation at $14,000 \mathrm{~g}$. Equal amounts of proteins from cell lysates were separated on $10-12 \%$ SDS-polyacrylamide gels (Invitrogen) under denaturing conditions and transferred onto Roti-PVDF 2.0 membrane transfer (Carl Roth GmbH+Co. KG, Karlsruhe, Germany). Non-specific binding was blocked with $2 \%$ non-fat dry milk or BSA ( $2 \mathrm{~h}$ ) in TBS (SantaCruz Biotechnology). The membranes were incubated overnight $\left(\right.$ at $4^{\circ} \mathrm{C}$ ) with the following specific antibodies (dilution 1/1000): antihuman AR: PA5-16750 (Thermo Fisher Scientific); antihuman MMP-2: AV20016 and anti-human MMP-9: AV33090 (Sigma-Aldrich Chemie GmbH); anti-human VEGF: MAB293R, anti-human Angiogenin: AF265, and anti-human EMMPRIN: AF972 (R\&D Systems). After TBS washings, the membranes were incubated with the corresponding HRP-conjugated secondary antibodies: anti-rabbit-HRP: AB6721 (Abcam); anti-mouse HRP: A9044 (Sigma-Aldrich), dilution $1 / 200,1 \mathrm{~h}$ at room temperature and examined by chemiluminescence (SuperSignal West Femto Maximum Sensitivity Substrate, Thermo Fisher Scientific). For control of protein loading, anti-beta-actin antibody (Santa Cruz Biotechnology) was used. The blots were scanned using a bioimaging system (ImageQuant LAS-3000 Chemiluminescence \& Fluorescence Imaging System, Fujitsu Life Sciences, Tokyo, Japan). Target signals were normalized against beta-actin and analyzed semi-quantitatively using the NIH Image system (ImageJ).

\section{Determination of NO produced by DHT-treated MSC}

These measurements were performed using the inNO-T system according to the published protocol (Alexandru et al. 2011). The NO released by MSC was measured after stimulation with 1,30 and $100 \mathrm{nM}$ DHT added at 10-min interval. In addition, to reveal the role of AR in

Table 1 qRT-PCR primers used for gene expression detection of MSC.

\begin{tabular}{lll}
\hline Primer (human) & Forward primer $\left(5^{\prime}-3^{\prime}\right)$ \\
${$\cline { 1 - 2 }$} }$ & GTTTCTATAAATTGAGCCCGCAG \\
MMP-2 & ACTACAACTTCTTCCCTCGCA \\
MMP-9 & GCCACTACTGTGCCTTTGAG \\
EMMPRIN & CTCACCTGCTCCTTGAATGAC \\
Androgen receptor & ATCCTTCACCAATGTCAACTCC \\
\hline
\end{tabular}

\begin{tabular}{l}
\hline Reverse primer $\left(5^{\prime}-3^{\prime}\right)$ \\
\hline CGACCAAATCCGTTGACTCC \\
GGCATCATCCACTGTCTCTG \\
CAGAGAATCGCCAGTACTTCC \\
GAGTCCACCTTGAACTCCGT \\
CCACTGGAATAATGCTGAAGAG
\end{tabular}

Primers were obtained using the PerlPrimer, V1.1.21 software. 
DHT-induced NO liberation, the cultured MSCs were stimulated for $45 \mathrm{~min}$ with an AR antagonist, flutamide (Sigma-Aldrich), and then the medium was changed and the NO measurements were taken.

\section{Preparation of murine cardiac tissue slices}

Experiments were done accordingly to the guidelines of the local animal welfare committee and approved by the ethical commission of the Institute of Cellular Biology and Pathology 'Nicolae Simionescu'. Under proper anesthesia, the hearts were removed from C57 black mice, and tissue slices were obtained using a vibratome apparatus according to Pillekamp and coworkers (Pillekamp et al. 2007). The sections were transferred in DMEM (1×) and GlutaMAX-I (Life Technology) containing 10\% FBS (Life Technology) and kept in the incubator under normoxic conditions $\left(37^{\circ} \mathrm{C}, 5 \% \mathrm{CO}_{2}, 21 \% \mathrm{O}_{2}\right)$.

\section{Evaluation of the interaction of MSC with cardiac tissue by chemotaxis assay}

xCELLigence system is a definite technique for real-time measurement of cell migration (Bird \& Kirstein 2009). We employed CIM plates, which are composed of two chambers separated by a porous membrane. We placed in the lower chamber, one murine cardiac slice and in the upper chamber 40000 MSCs that were stimulated with DHT or exposed to the vehicle (controls). In both chambers, DMEM (1×) with GlutaMAX and 10\% FBS and 1\% Antibiotic Antimycotic Solution (Sigma-Aldrich) was used. The CIM plates were kept in an incubator under normoxic conditions (as above). To evaluate the role of ARs in the migration process, MSCs in the CIM plate system were exposed to flutamide for $45 \mathrm{~min}$ prior to the experiment. The cell migration was monitored for $12 \mathrm{~h}$. The determinations were done in quadruplicate, and the experiments were repeated at least three times.

\section{Analysis of proteins secreted by MSC upon interaction with cardiac tissue by ELISA and Luminex techniques}

For these experiments, $24 \mathrm{~mm}$ Transwell with $0.4 \mu \mathrm{m}$ pore polycarbonate membrane inserts and TC treated (Corning) were used. Murine heart slices were placed in the lower chamber and 40,000 MSCs/well treated or not with DHT were placed in the upper chamber. Both cells and tissues were maintained in DMEM medium $(1 \times)$ with GlutaMAX containing 10\% FBS, 1\% antibiotic antimycotic solution and were kept in an incubator under normoxic conditions.
For each experimental condition, after 24 and $48 \mathrm{~h}, 1.5 \mathrm{~mL}$ of conditioned medium was harvested from the lower chamber and MMP-2 and MMP-9 were determined by ELISA assay.

Similar experiments were performed to assess angiogenin and VEGF by Luminex technique using Human Angiogenic Panel A (BD Bioscience) according to the manufacturer's protocols.

\section{Detection of MSC adherence and integration into cardiac tissue slices by immunohistochemistry}

In a 48-well TC-treated plate (Corning), $250 \mu \mathrm{m}$ thick murine heart slices were placed in DMEM medium (1x) with GlutaMAX, 10\% FBS CS and 1\% antibiotic antimycotic solution. Then, 40,000 MSC/well non-treated or treated with DHT for $96 \mathrm{~h}$ prior to co-cultivation were seeded in direct contact with the heart slices. After $72 \mathrm{~h}$, the heart fragments were washed twice with PBS and subjected either to immunohistochemical staining or to DNA quantification for cell counting (see below). For immunohistochemistry, the heart fragments were fixed overnight in $4 \%$ paraformaldehyde, embedded in paraffin, $2 \mu \mathrm{m}$ sections cut with a microtome (DTK-2000, Dosaka, Kyoto, Japan), placed on slides, deparaffinized and rehydrated with successive concentrations of xylene and ethanol (100, 95, 70 and 50\%). To ease the binding of antibodies, the heat-induced epitope retrieval was performed by placing the sections kept in sodium citrate buffer in a pressure cooker for $3 \mathrm{~min}$. To evaluate the integration of human MSC in the murine ventricular slices, we have employed anti-human nuclei antibody (1:100, Sigma-Aldrich) followed by anti-mouse HRP: A9044 (Sigma-Aldrich). As substrate for the detection system, we used 3,3'-diaminobenzidine (DAB) (SigmaAldrich) that formed a brown color precipitate in the presence of HRP and $\mathrm{H}_{2} \mathrm{O}_{2}$.

\section{Determination of MSC adherence and integration into cardiac tissue slices by DNA quantification using qRT-PCR}

For these experiments, we have used Real-time PCR 7900 HT (as described earlier) TaqMan Universal PCR Master Mix-4304437, Human GAPDH- Hs03929097_g1 and a 384-well PCR plate (Thermo Fisher Scientific). Human MSCs (40,000 cells), untreated or DHT treated (30 nM), were incubated as described earlier for immunocytochemistry experiments. After $48 \mathrm{~h}$, the DNA was isolated using the PureLink Genomic DNA Minikit (Life Technologies) and quantified by NanoDrop ND-1000 
UV-VIS spectrophotometer. For the calibration curve, serial 10-fold dilutions of standard DNA isolated from 2500 to 40,000 MSCs were prepared. Standard curves and the amplification conditions were established as in study by Àlvarez (Àlvarez et al. 2013). In addition, human vs mouse genes comparison was assayed using GenomeArtist (Ecovoiu et al. 2016).

The experimental conditions for the PCR were set according to the manufacturer specification. All experiments were performed in triplicate.

\section{Liquid chromatography-mass spectrometry (LC-MS) analysis of MSC}

All reagents were of electrophoresis or LC-MS grade. Urea, sodium deoxycholate (DOC), trizma hydrochloride (Tris-HCl), DL-dithiothreitol (DTT), iodoacetamide (IAA), $\mathrm{N}$-acetyl-L-cysteine (NAC), ammonium bicarbonate and MS solvents were from Sigma-Aldrich. Trypsin Gold was from Promega, the protease inhibitors from Roche and solid phase extraction C18 columns from Waters (Milford, MA, USA). ADV-01A kit from Tebu-Bio (Le Perray-enYvelines, France) was employed for protein quantification. The cells were washed twice with PBS, centrifuged and the pellet was solubilized in a denaturant buffer containing $8 \mathrm{M}$ urea, $1 \%$ DOC, $0.1 \%$ Tris- $\mathrm{HCl}(\mathrm{pH} 8.8)$ and protease inhibitors, using sonication pulses for $30 \mathrm{~s}$, on ice (UP5OH from Hielscher, Teltow, Germany). Protein purification, carbamydomethylation, proteolysis and solid-phase extraction were performed as previously described (Suica et al. 2016).

LC-MS/MS analysis was carried out using the EASY n-LC II system (Thermo Scientific) coupled to the LTQ Orbitrap Velos Pro mass spectrometer (Thermo Scientific), working in a Top12 data-dependent analysis, with $60 \mathrm{k}$ resolution, as described (Boteanu et al. 2016). Three biological replicates, each with three technological replicates were processed and analyzed for the proteomics workflow. The bioinformatics analysis comprised database protein inference, relative quantification and Kyoto Encyclopaedia of Genes and Genomes (KEGG) signaling pathways over-representation and was performed as previously described (Uyy et al. 2016).

\section{Statistical analysis}

The data were analyzed by a one-way ANOVA either with the QtiPlot - 0.9.8.9 (ProIndep Serv S.R.L., Craiova, Romania) or by two-tailed unpaired $t$ tests with the GraphPad Prism 4 software (GraphPad Software).
The statistics are presented as mean \pm S.E.M. and differences were considered statistically significant when $P$ value was $<0.05$.

\section{Results}

\section{DHT augments MSC proliferation without affecting} their morphology

Since circulating levels of testosterone range between 8 and $42 \mathrm{nM} / \mathrm{L}$, we first tested the effects of $1-1000 \mathrm{nM}$ of DHT on the growth of MSCs. Treatment of MSCs with 1-1000 nM DHT-induced cell proliferation, but not cell death. Subsequently, we elected to use a concentration of $30 \mathrm{nM}$, which is comparable to the circulating levels of testosterone and induced MSC growth with no toxicity. Hence, this concentration was further used in most of the experiments. It must be emphasized that the circulating levels of DHT are 10-fold lower $(\approx 3 \mathrm{nM})$ and its affinity for ARs is $\approx 3$-fold higher than that of testosterone.

Examination of MSC after 1 and 4 days in culture showed that the DHT-treated MSC exhibited a similar morphology and viability with the non-stimulated cells; however, a definite increase in cell density in stimulated cells compared to non-treated MSC was noticed (Fig. 1A).

In addition, MSC proliferation was evaluated in realtime for $160 \mathrm{~h}$ using xCELLigence system. In this system, the quantification of the cellular index (CI) calculated from the cellular impedance measurements is directly proportional with the number of cells per well. Our experiments revealed that DHT-treated MSC exhibited a significantly increased CI compared to non-treated cells indicating enhanced proliferation of MSC in the presence of DHT (Fig. 1B).

To verify and confirm that CI correlates directly to the increase in cell number, we performed a proliferation assay consisting in DNA quantification. The results showed that DHT stimulation increased the number of MSC with more than 20,000 cells per well after 6 days in culture, which is a 3 -fold increase compared to control, cells treated with DMSO (vehicle) (Fig. 1C). The data corroborate well with those obtained using xCELLigence system, showing that DHT stimulation induces an increase in MSC proliferation rate.

\section{DHT induces in MSC upregulation of the gene expression of ARs and of the genes involved in cell migration, EMMPRIN and MMP-9}

To find out whether DHT affects the gene expression of ARs and of other molecules implicated in cell migration, 
A
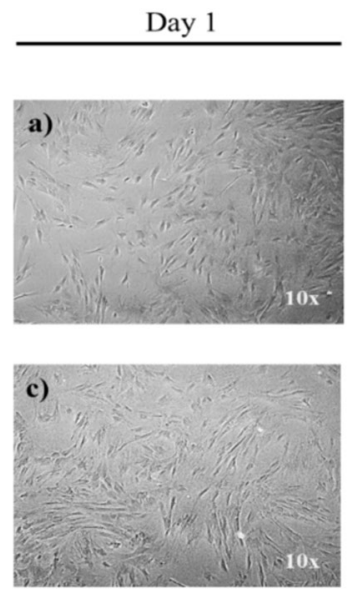

Day 4
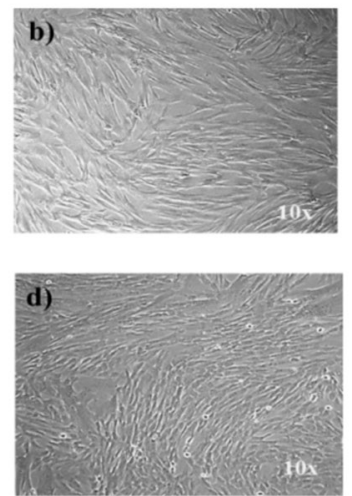

B
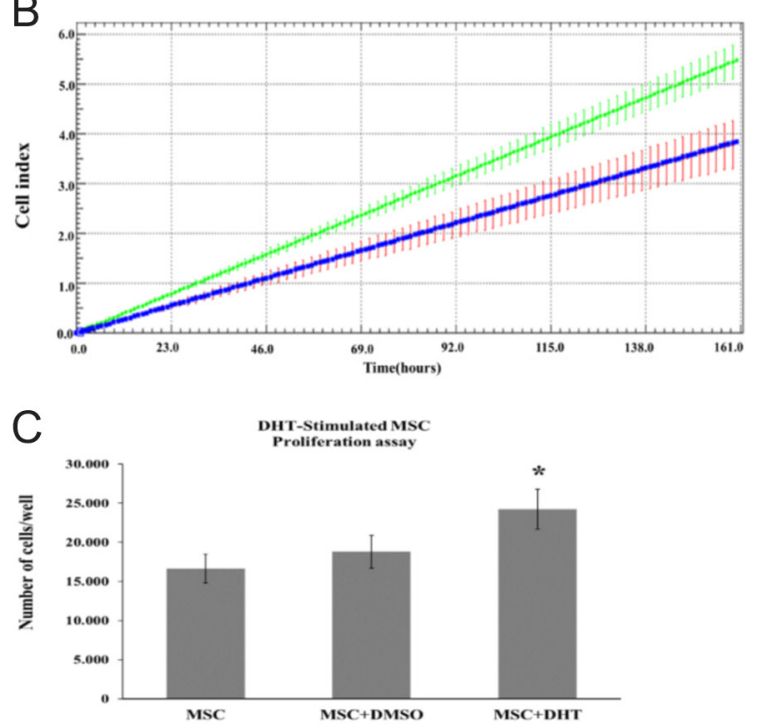

Figure 1

Exposure of MSC to DHT maintains the cell morphology but increases significantly their proliferation. (A) Morphology of cultured non-treated MSC ( $a$ and $b$ ) and of MSC exposed in vitro to DHT ( $c$ and d). Compared to controls (day 1), at 4days, DHT enhances proliferation, maintains the cell phenotype and is non-toxic for cells. (B) Proliferation of MSCs (7000 cells/well) grown in DMEM $1 \%+10 \%$ FBS $+1 \%$ antibiotics in the absence (control) or presence of DHT or exposed to vehicle only, for $160 \mathrm{~h}$. As assessed by the cell index value, the proliferation of DHT-stimulated MSC (green) increases steadily and is above the values of non-stimulated cells (blue) or vehicle-exposed cells (green) for $160 \mathrm{~h}$. (C) Determination of MSC proliferation using DNA quantification-CyQuant. The cells (7000 cells/well) were cultured in DMSO (DHT-vehicle) or in the presence of DHT (MSC+DHT) and after 6 days, lysed and prepared for DNA quantification according to the manufacturer instructions. Note that DHT induces a significant increase in the number of MSC compared to controls. ${ }^{*} P<0.05, n=3$.

cultured MSC were exposed to the hormone (30 nM) and then subjected to qRT-PCR assay. The experiments revealed that DHT induced a significant upregulation of the mRNA for AR and of the molecules involved in cell migration, EMMPRIN and MMP-9; DHT had no effect on MMP-2 gene expression (Fig. 2).

\section{DHT induces changes in protein expression of AR, EMMPRIN, angiogenin and MMP-9}

Western blot assay showed that, compared to nonstimulated cells, the DHT-treated MSCs exhibit a significant increase in protein expression of ARs, EMMPRIN,
A

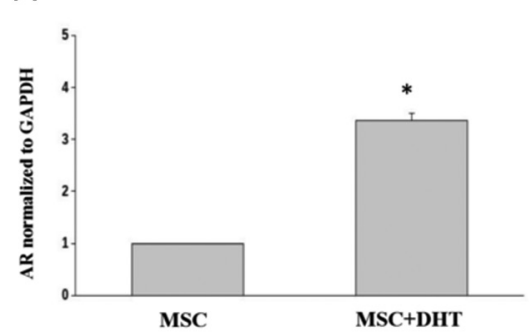

C

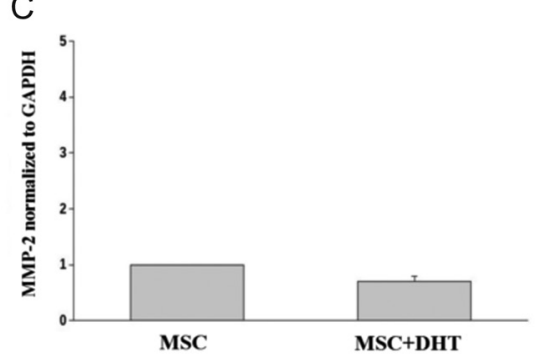

B

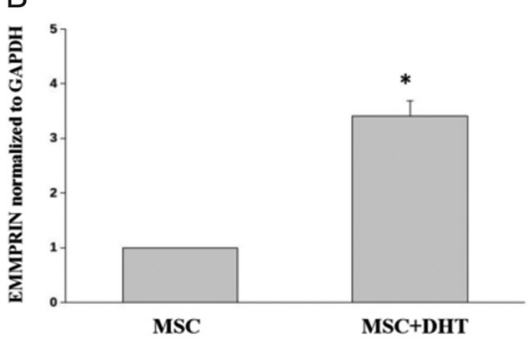

D

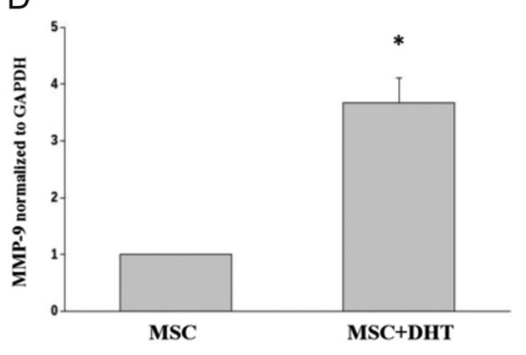

Figure 2

Exposure of MSC to $30 \mathrm{nM}$ DHT (MSC +DHT) increases gene expression of AR (A), EMMPRIN (B) and MMP-9 (D) and does not affect MMP-2 mRNA (C). The quantification of gene expression was done by qRT-PCR assay. Data are expressed as means of fold expression (relative quantification) values ( \pm ) S.E.M. of each gene in comparison with GAPDH and normalized to an arbitrary value of 1 . Significant $P$ values are indicated in the graphics and calculated from arbitrary value ANOVA tests. $n=3$. * $P$ value $<0.05$ 
angiogenin and MMP-9. The expression of MMP-2 and VEGF were not modified by DHT as compared to the non-treated MSC (Fig. 3). Remarkably, the DHT-induced changes in the protein expression of AR, EMMPRIN and MMP-9 were paralleled by comparable increase in their gene expression in MSCs (Fig. 2).

\section{DHT stimulates NO production in MSC via an AR mechanism}

These experiments examined whether the MSCs respond to different DHT concentrations (1, 30 and $100 \mathrm{nM})$ by releasing increased concentration of $\mathrm{NO}$ in the culture medium; the NO production was monitored with a specific NO sensor. It was detected that, in the presence of different DHT concentrations, the MSC produced approx. 2.5-fold more NO compared with the values (baseline) obtained for non-treated MSC, and this was independent of the hormone concentrations (Fig. 4A and B).

In MSCs pretreated for $45 \mathrm{~min}$ with flutamide $(10 \mu \mathrm{M})$, an androgen receptor antagonist, the stimulatory effects of DHT on NO secretion were blocked to basal levels, suggesting that the stimulatory effects of DHT on NO secretion are AR mediated (Table 2). These observations provide evidence that the concentration-dependent stimulatory effects of DHT on NO secretion are AR mediated.

\section{DHT enhances migration of MSC toward the murine cardiac slices}

To find out whether DHT influences the migration of MSC toward heart tissue, we set up co-culture experiments utilizing human MSC and murine cardiac tissue slices
A
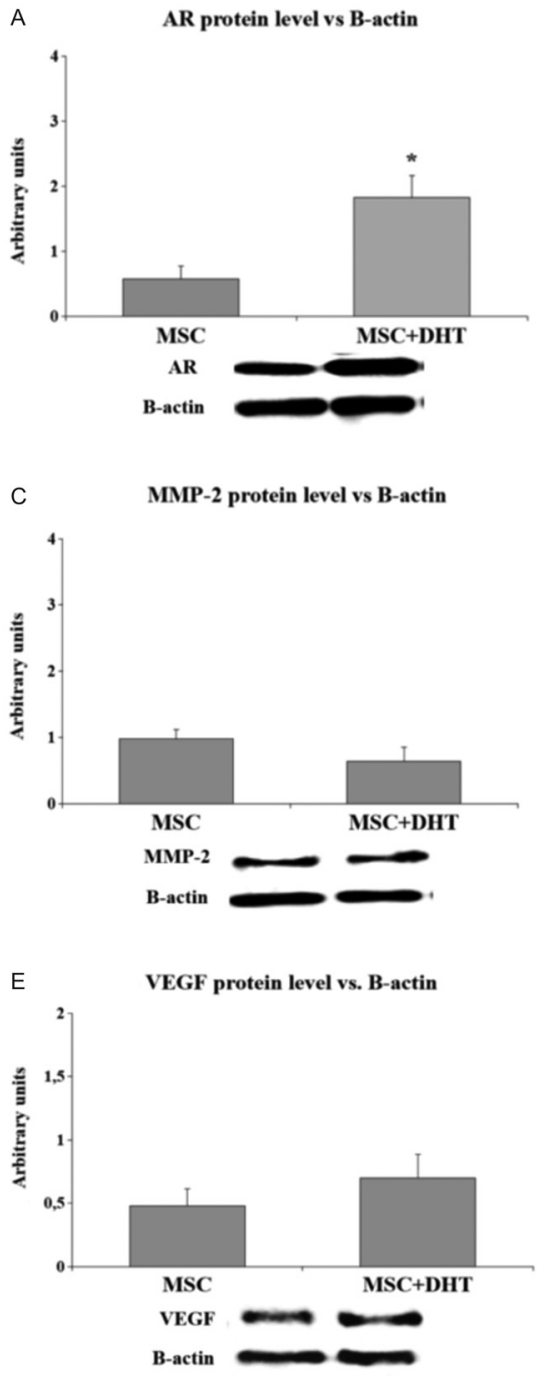
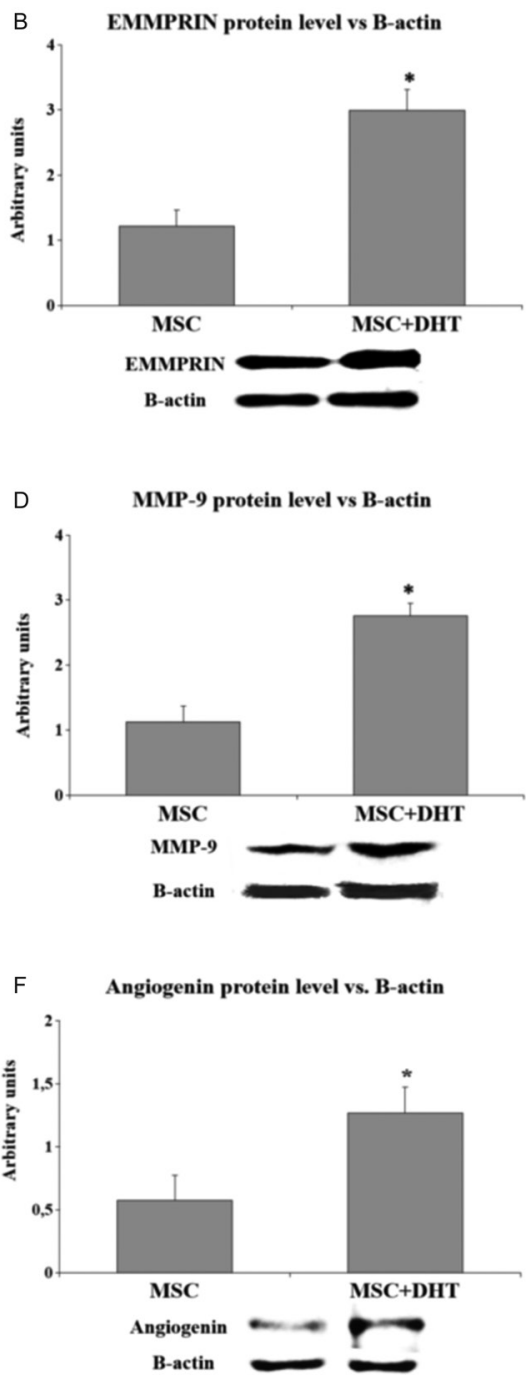

Figure 3

DHT increases significantly the protein levels of AR, EMMPRIN, MMP-9 and angiogenin in MSC. Cultured cells were stimulated with $30 \mathrm{nM}$ DHT and subjected to Western blot assay. As shown earlier by gel electrophoresis and morphometric analysis, compared to non-stimulated MSC (controls), DHT induces a significant increase in protein expression of androgen receptor (A, AR), EMMPRIN (B), MMP-9 (D) and angiogenin (F) and has no effect on MMP-2 (C) and VEGF (E). All the results were normalized to beta-actin; ${ }^{*} P$ value $<0.005$ in comparison with control cells were considered statistically significant. $n=3$. 

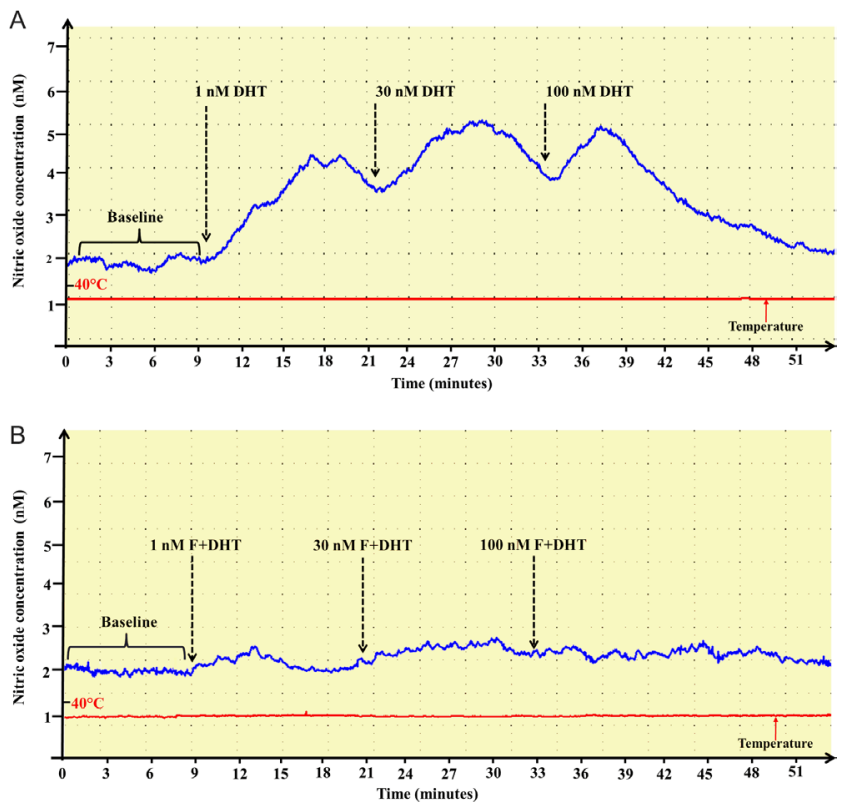

Figure 4

DHT-treated MSC exhibit augmented NO release. The cells were exposed in culture either to different concentration of DHT $(1,30,100 \mathrm{nM})(\mathrm{A})$ either to flutamide (F) and DHT (B). NO release was determined in the culture medium using an amperometric NO sensor. Each measurement was done separately for $t=10 \mathrm{~min}$; Baseline is considered $0 \mathrm{nM}$.

( $250 \mu \mathrm{m}$ thick). The results obtained using xCELLigence system showed that the rate of migration of hormonetreated MSC toward the cardiac tissue was constantly higher than the values obtained for migration of control or vehicle-exposed cells. The migration of stimulated MSC was about two folds higher during and at the end of the $14 \mathrm{~h}$ of measurements. To find out if ARs are involved in cell migration toward heart, we performed similar experiments in the presence of flutamide, to impair the hormone action by blocking its receptor (Fig. 5A and B). The results showed that blocking the ARs, the cell migration, as expressed by the CI, was limited to the values obtained in controls.

Table 2 Quantification and statistical analysis of the NO concentration in the culture medium of MSC exposed to 1, 30 and $100 \mathrm{nM} \mathrm{DHT}$ in the absence or presence of flutamide.

\begin{tabular}{|c|c|c|c|}
\hline $\begin{array}{l}\text { Dihydrotestosterone (DHT) } \\
\text { concentrations }\end{array}$ & $1 \mathrm{nM}$ & $30 \mathrm{nM}$ & $100 \mathrm{nM}$ \\
\hline No concentration (nM) & $2.5 \pm 0.4$ & $2.6 \pm 0.72$ & $2.3 \pm 0.35$ \\
\hline $\begin{array}{l}\text { No concentration (nM) in } \\
\text { the presence of flutamide }\end{array}$ & $0.5 \pm 0.14$ & $0.32 \pm 0.25$ & $0.45 \pm 0.13$ \\
\hline
\end{tabular}

Note that at all DHT concentrations used, flutamide blocks the NO values indicating that, also androgen receptors are implicated in NO stimulation; $n=4$.
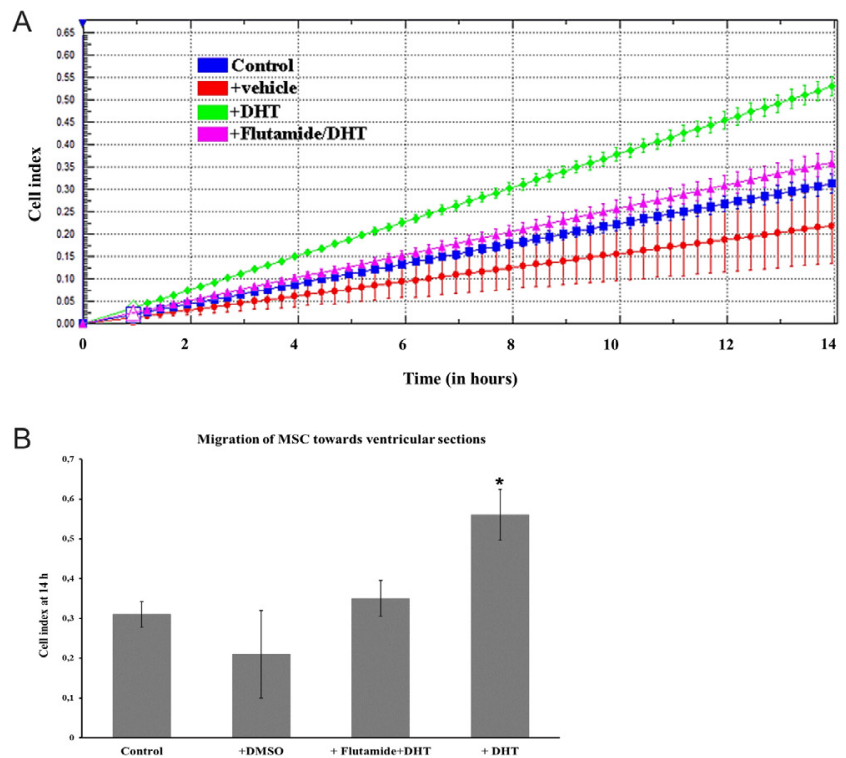

Figure 5

( $A$ and $B$ ) Migration of MSC toward murine ventricular slices is significantly increased by prior exposure of the cells to DHT. As revealed by real-time based measurements (xCelligence system) for $14 \mathrm{~h}$. The cell index that signifies the number of cells that migrate toward the heart slices (Hs) shows increased migration of DHT-treated MSC (green) toward the murine Hs compared to non-treated MSC (blue), vehicle-treated MSC (red) and flutamide (AR inhibitor)-treated MSC (pink). Experiments were performed in quadruplicate for at least three times.

\section{DHT-treated MSCs exhibit increased adherence/integration into cardiac slices}

To validate the earlier results and achieve robust evidence of MSC migration and integration into murine cardiac slices, we apply for immunohistochemical staining using anti-human nuclei antibody that could detect particularly human MSC within the sections.

Examination of the tissue sections incubated with anti-human nuclei antibody followed by an HRP-labeled secondary antibody revealed the brownstained MSC nuclei and the blue, hematoxylin stained, mouse cell nuclei. We found that in comparison with non-treated MSC, the number of DHT-treated human MSC is considerably higher (Fig. 6A and B). As antibody control, we used IgG isotype (Fig. 6C). The data were validated by digital counting using ImageJ software indicating a significant difference between non-treated and treated MSC integration within heart tissue (Fig. 6D).

Because of the limited volume of tissue that can be examined by immunocytochemistry, we apply for a quantitative method, the qRT-PCR. Evaluation of human DNA revealed that the total number of human hormonetreated MSC adhered and integrated within the cardiac 
A

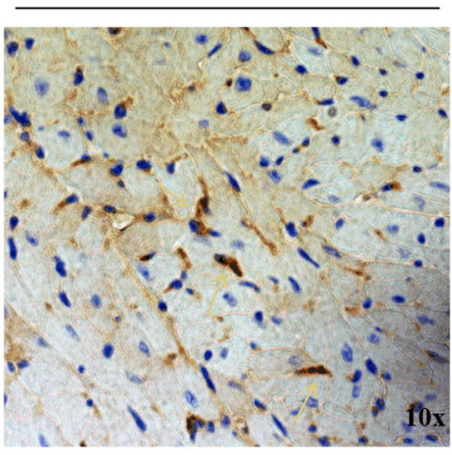

B DHT-treated MSC

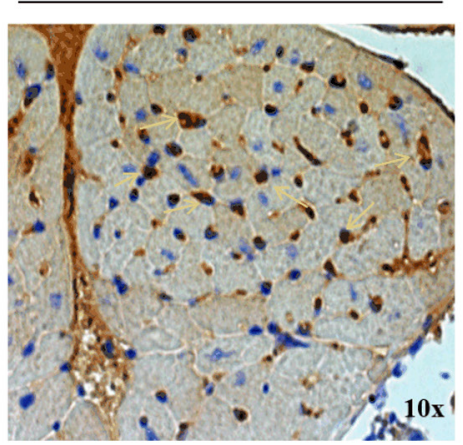

E Control-IgG

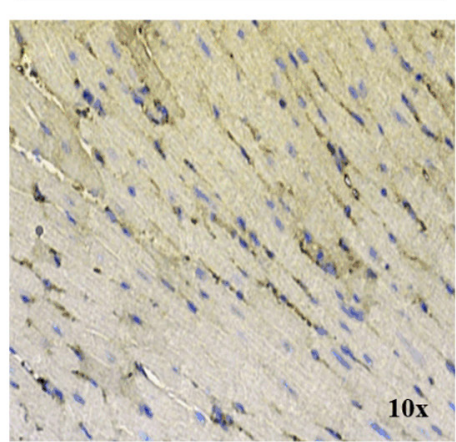

C

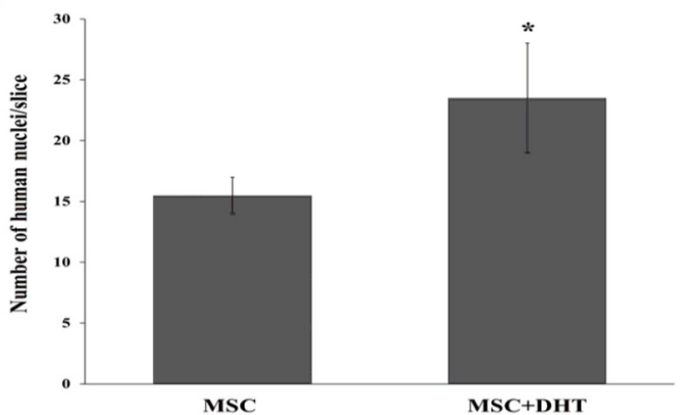

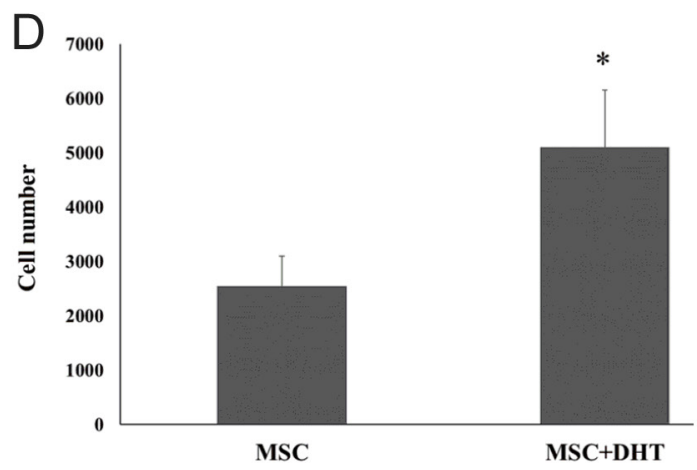

\section{Figure 6}

Identification of the integration of DHT-treated MSC into the heart tissue slices by immunohistochemistry. MSC were co-cultured for $48 \mathrm{~h}$ with heart tissue slices $(250 \mu \mathrm{m}$ thick) and then the tissue was washed and embedded in paraffin. The $2 \mu \mathrm{m}$ sections were incubated with anti-human nuclei antibody followed by an HRP-labeled secondary antibody. The peroxidase reaction stains in brown the MSC nuclei, whereas the hematoxylin stains the mouse cell nuclei in blue. Note that in comparison with non-stimulated MSC (A), a significantly higher number of nuclei are stained (brown) in the heart slices co-cultured with DHT-stimulated human MSC (B). As antibody control, the IgG isotype was employed (C). In (D) digital counting of the results using ImageJ software shows that the number of stained human MSC nuclei is significantly higher in the case of stimulated cells (MSC+DHT). For each section, 4 different fields were analyzed $(n=3)$. (E) Quantification of the number of MSC adhered/integrated into heart slices after co-culture for $48 \mathrm{~h}$ assessed by human DNA analysis (qRT-PCR). $n=3$. * $<0.05$ as compared to non-treated cells.

slices was $\sim 50 \%$ higher than that for the non-stimulated cells (Fig. 6E).

\section{Incubation of DHT-treated MSC with heart tissue increases the cell secretion of MMP-2 and MMP-9}

To determine whether migration-stimulating factors are released after co-culture of stimulated MSC with cardiac slices, we employed a Transwell system in which the cells and the cardiac sections were placed in the upper and respectively lower chamber, which is in indirect contact. After 24 and $48 \mathrm{~h}$, the culture medium was collected and analyzed using human-specific ELISA kits. We have detected that MMP-2 and MMP-9 were significantly increased, both at 24 and $48 \mathrm{~h}$ of co-cultivation of DHTtreated MSC with cardiac slices as compared to controls in which non-treated MSC were employed. The difference was, in particular, higher after $48 \mathrm{~h}$ (Fig. 7A, B, C and D).

\section{Exposure of hormone-treated MSC to cardiac tissue slices upregulates the cell secretion of angiogenin and VEGF}

Analysis by fluorescence-based multiplex cytokine assay (Luminex) of the conditioned medium collected from DHT-treated MSC incubated (in a Transwell system) with cardiac tissue slices revealed a significant upregulated secretion of angiogenin (at 24 and $48 \mathrm{~h}$ ) and of VEGF at 48 h (Fig. 7E and F).

\section{Upregulation of actin cytoskeleton in DHT-treated MSC as revealed by liquid chromatography- mass spectrometry}

A total of 3180 protein groups were unambiguously identified using high-resolution mass spectrometry, of which 2320 were identified in both groups, while 490 proteins could be uniquely attributed to the effects of DHT 
A
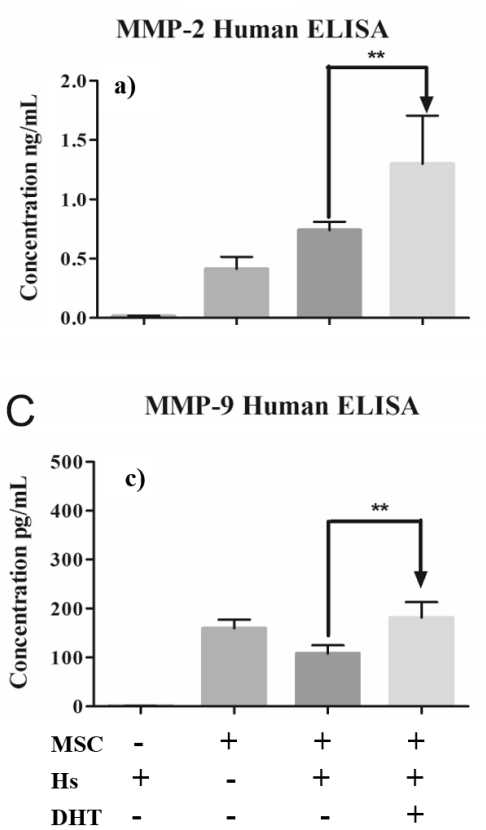

E

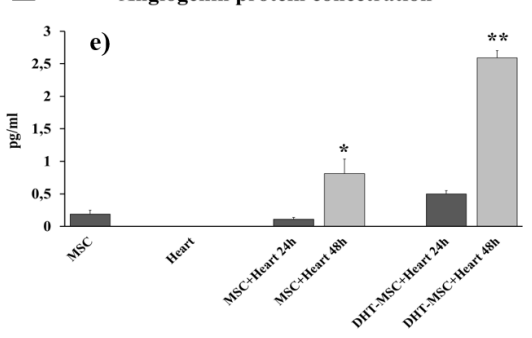

B
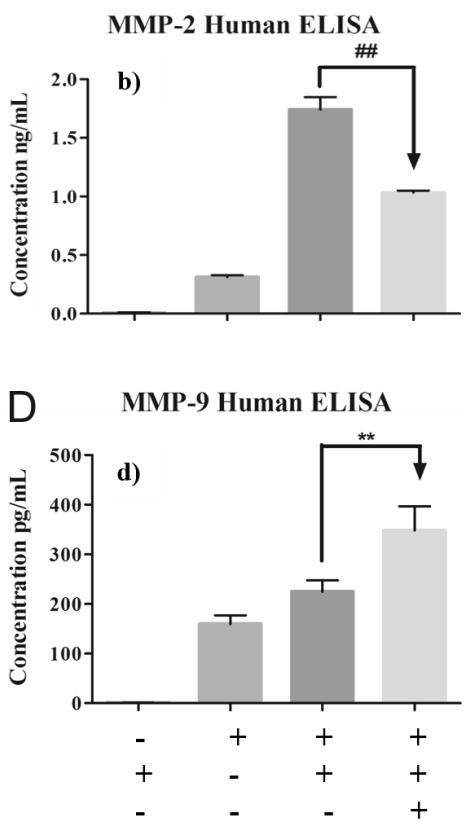

F

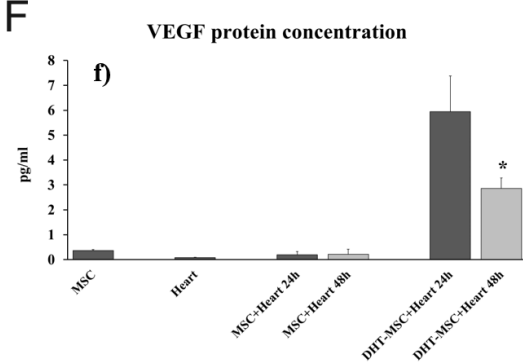

\section{Figure 7}

Secretion of MMP-2 (A and B), MMP-9 (C and D), angiogenin (E) and VEGF (F) by DHT-treated $(30 \mathrm{nM}) \mathrm{MSC}$ kept in indirect contact with heart tissue slices (Hs) is significantly increased compared to controls (non-stimulated MSC). The experiments were performed in Transwell plates, for 24 and $48 \mathrm{~h}$, and the proteins were quantified by ELISA and Luminex assay using human antibodies (to evidence human MSC). ${ }^{*} P<0.05$; $* *<0.001$, \#\#P value $<0.005$ in comparison with control cells (non-stimulated) were considered statistically significant. $n=3$. treatment on MSC (Fig. 8A). The relative quantification experiments were based on precursor ion alignment and intensity comparison between the DHT-treated and the control MSC. A coefficient of variation of $<30 \%$ was allowed between technical replicates. The total ion chromatogram normalization method resulted in 869 proteins that are differentially expressed following the treatment with DHT. A supplementary filtration, allowing only the proteins quantified with at least 2 peptides/protein, was chosen for further bioinformatics analysis. This resulted in a list of 258 proteins with spectral abundance alteration of at least 1.5-fold (DHT treatment/control samples) and statistical significance (Fig. 8B). Among them, four proteins, which presented very high identification confidence (Mascot score >9000) and significant spectral alteration levels (Table 3) were found to be part of a key cell motilitysignaling map, the regulation of actin cytoskeleton (KEGG entry hsa04810). This pathway was found to be statistically over-represented, after the implementation of a further significance correction, which was based on the false discovery rate algorithm (FDR $P$ value: $1.96 \mathrm{E}-2$ ).

\section{Discussion}

The pluripotent nature of adult MSC is of great therapeutic interest to treat heart damage following myocardial infarction, reperfusion injury succeeding ischemia and heart/vascular damage. Certainly, it may provide the only alternative to heart transplantation as a permanent cure for heart damage (Nesselmann et al. 2008, Karantalis \& Hare 2015, Singh et al. 2016). The availability of MSC from multiple body sources and the fairly simple in vitro propagation of the cells to the desired cell type as well as the lack of ethical problems have made these cells a favorite source for stem cell therapy. The last decade has seen multiple animal and clinical studies assessing the efficacy of MSC in repairing damaged heart (Singh et al. 2016). Although, MSC-induced protective effects were 

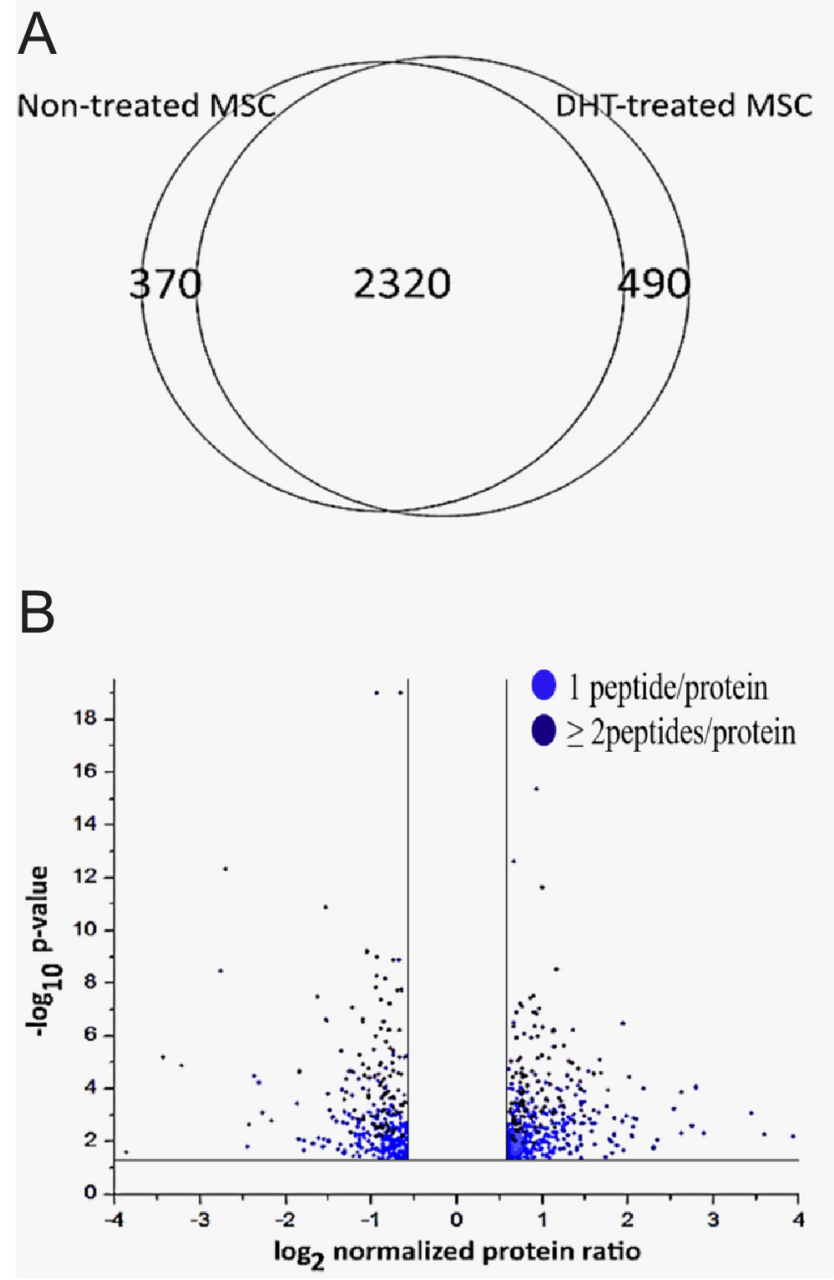

Figure 8

Nano chromatography-mass spectrometric analysis of non-treated control MSCs and DHT-treated MSCs. (A) Qualitative analysis revealed the identification of 3180 proteins, of which 370 proteins were only attributed to non-treated MSCs, while 490 proteins were uniquely identified in the samples following DHT treatment; (B) the label-free relative mass spectrometric quantification demonstrated the spectral abundance alteration of 869 proteins (blue dots), 258 of them being quantified with at least 2 peptides/protein (dark-blue dots), passing the abundance ratio (vertical lines signify the $\log _{2}$ normalized ratio of 0.67 and 1.5 , respectively) and the significance criteria (horizontal line represents the $-\log _{10} P$ value of 0.05 ).

observed in most, but not all, studies, the consensus is that the integration of MSC is low and novel strategies promoting their homing-in and integration need to be further developed to make MSC therapy successful.

Sex steroids are known to directly affect human bone marrow stromal cells; however, the biological mechanisms involved remain unclear. In vitro experiments revealed that male sex hormones, i.e. androgens, induce endothelial cell growth, suggesting that androgens may influence the cardiovascular system via angiogenic actions
(Sieveking et al. 2010). Thus, we set up experiments to find out whether exposure of MSC to androgens has a beneficial effect on the cell's characteristic functions. In prior experiments, we have used testosterone (Corotchi et al. 2016) to assess its effects on the growth of MSCs. We found that the growth stimulatory effects of testosterone and DHT were comparable, although testosterone was marginally more potent than DHT (MSC growth was induced, by approximately 3.86-fold and 3.4-fold, in response to testosterone and DHT, respectively). Hence, for further experiments, we employed DHT because it is a most potent testosterone derivative with the high affinity for AR, and it is not metabolized to estradiol.

The following novel findings were revealed by our experiments with MSCs: (a) DHT increased proliferation, migration and chemotaxis via mechanism(s) involving ARs; (b) DHT modulated MMP-2 and MMP-9 levels; (c) enhanced cell migration toward cardiac tissue and (c) secretion of angiogenin, VEGF and NO - key factors involved in the invasion and integration of cells into ischemic tissue that attempts to regenerate.

We found that the secretion of MMPs is increased significantly in DHT-treated MSC, and this effect was specifically enhanced in the presence of heart slices. These results suggest the possibility that factors generated by ischemic tissue stimulates MSC to increase the MMPs production, and this response supports the proteolytic activity (Fig. 9), which is essential for clearing damaged scar tissue so as to facilitate MSC integration and tissue repair. Taken together, the earlier findings suggest that DHT potentiates the integration of MSC into cardiac tissue, and thus, may positively influence the repair process.

The participation of MMP's and VEGF in angiogenesis is well established as they facilitate the cell migration and are pro-angiogenic factors (Ries et al. 2007, Mias et al. 2009). The spatiotemporal regulation of MMP-2 and MMP-9 have been observed, following myocardial infarction and end-stage heart failure suggesting that they are involved in the cardiovascular remodeling (Deschamps \& Spinale 2006). Secreted MMPs are key markers for cell migration under normal and pathological conditions (Spinale \& Wilbur 2009). Increased presence of MMP-2 is indicative of deleterious recovery following ischemic heart injury, whereas sustained expression of MMP-9 facilitates recovery and post-ischemic heart reconstruction (Cheung et al. 2000). Our observation that DHT induced MMP-9, but not MMP-2 in MSCs, suggests that DHT induces beneficial MMPs under normal conditions. The fact that MMP-2 secretion was 
Table 3 Spectral abundance alteration level and significance of the proteins that determined the statistical over-representation of regulation of actin cytoskeleton KEGG signaling pathway.

\begin{tabular}{|c|c|c|c|c|}
\hline Uniprot acc. code & Description & Molecular weight $(\mathrm{kDa})$ & Median Mascot score & Median ratio (DHT-treated MSCs/non-treated MSCS) \\
\hline P02751 & Fibronectin & 262.625 & 9465.2 & $0.633 \pm 0.04 * * *$ \\
\hline P05556 & Integrin beta-1 & 88.415 & 50678.0 & $1.8173 \pm 0.201 * * *$ \\
\hline P26038 & Moesin & 67.820 & 73389.0 & $0.623 \pm 0.07 * * *$ \\
\hline P35579 & Myosin-9 & 226.532 & 11640.0 & $1.589 \pm 0.06 * * *$ \\
\hline
\end{tabular}

Data include the Uniprot database accession entry, molecular weight and median Mascot identification score. ${ }^{* \star * P<0.001}$.

induced, when MSCs were co-incubated with heart slices suggests that factors generated from sliced (injured) heart trigger MMP-2 generation to potentially facilitate early proteolytic activity for clearing the scar tissue and to facilitate subsequent angiogenic and tissue growth/ integration process (Ries et al. 2007, Mishra et al. 2013, Nam et al. 2015). The observation that DHT attenuated MMP-2 expression in MSCs co-incubated with heart slices after $48 \mathrm{~h}$, but increased MMP-9 expression suggests that DHT regulates MMP-2 and MMP-9 in a spatio-temporal fashion to facilitate tissue recovery.

Both MMP-2 and MMP-9 possess gelatinase activity and have a considerable overlap in substrates they degrade; however, MMP-9 is incapable of direct proteolysis of collagen I (Klein \& Bischoff 2011). Evidence also suggests that MMP-2 and MMP-9 have distinct roles in tissue remodeling, and these effects are regulated in a spatiotemporal fashion by paracrine factors generated following injury (Ries et al. 2007, Klein \& Bischoff 2011, Mishra et al. 2013, Nam et al. 2015). Knockout models of MMP-9 exhibit delayed apoptosis, vascularization

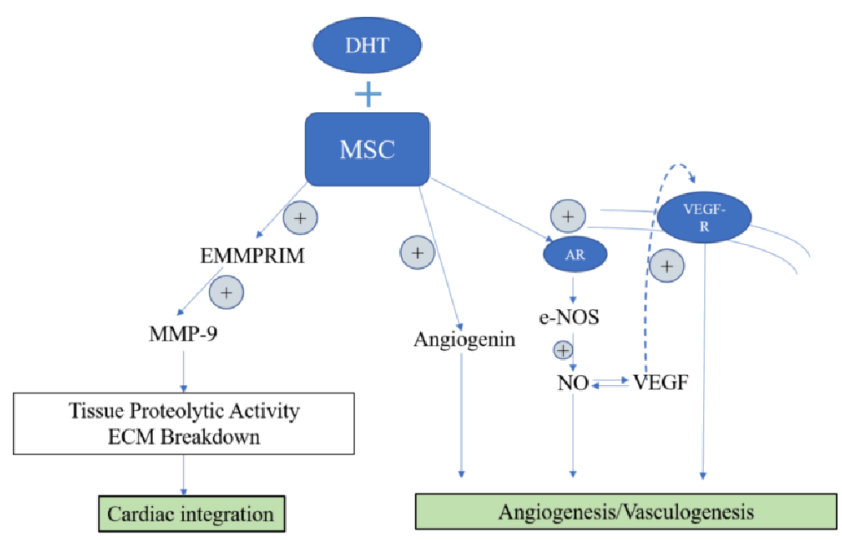

Figure 9

Schematic representation of DHT-induced pro-repair mechanisms in MSCs. Our data indicate that DHT stimulates proliferation and migration of MSC by a process in which increased expression of EMMPRIN, MMP-9 potentially promotes their homing-in and cardiac integration. Additionally, DHT induces expression of angiogenin, VEGF and of AR-dependent NO release that may participate in the process of angiogenesis and vasculogenesis. and ossification of hypertrophic chondrocytes. MMP-2 degrades extracellular matrix (ECM) protein and cleaves other non-ECM substrates including pro-TNF, FGF receptor-1, TGF-B, IL-1B and various chemokines. Treatment with DHT increased the expression of MMP9, and EMMPRIM in MSC suggests that androgens can potentially activate mechanisms critical for initiating tissue repair and remodeling. This would be similar to the reported sprouting angiogenesis in endothelial cells, which release proteolytic enzymes, including MMPs and VEGF in order to induce angiogenic signaling efficiently ( $\mathrm{Wu}$ et al. 2007, Cai et al. 2016). Our findings also demonstrate that the stimulatory effects of DHT on the expression of both, cell migration and pro-angiogenic factors, such as MMP-9, VEGF and angiogenin are maintained up to $48 \mathrm{~h}$. These results imply that MSC could be involved in angiogenesis either through differentiation or via a paracrine effect. Furthermore, we demonstrate that DHT enhanced chemotaxis of MSC toward the cardiac slices and stimulated their adhesion and integration within this tissue. Our findings suggest that synthesis of MMPs is potentially influenced by EMMPRIN, could regulate myogenic cell differentiation (Mohamed et al. 2011) and provide the first evidence for an association between EMMPRIN and MMPs in a co-culture model using hormone-treated MSC.

At the functional level, our results demonstrate that cultured human MSC are capable of synthesizing NO constitutively. Moreover, we provide evidence that stimulation of MSC with androgens increased the NO release as measured in real time in the culture medium, and this secretion is blocked in the presence of the AR antagonist. The significance of the increase in constitutive NO production in MSC can only be speculated. Since NO is a key mediator for angiogenesis (Losordo \& Isner 2001), we assume that stimulation of basal NO production by DHT in human MSC participates in promoting/improving the capillary network around the ischemic sites. Our observation that DHT induces both VEGF and NO suggests that the pro-angiogenic effects of DHT may be mediated via a cross-talk between them. Moreover, this may create 
a synergistic environment as VEGF has been shown to induce angiogenesis via NO generation and NO induces VEGF thereby creating a positive feedback angiogenic loop (Papapetropoulos et al. 1997, Losordo \& Isner 2001, Ikeda et al. 2012).

The experiments showing that the number of DHTtreated MSC integrated in the cardiac slices was higher than that of non-treated cells provide evidence that the hormone facilitates homing-in and integration of MSC. The fact that quantification of the integrated cells was assessed using 2D techniques, which monitor cells stained within the 2nd or 3rd layer at a depth of $\approx 2 \mu \mathrm{m}$ within the tissue reaffirms the notion that DHT promotes MSC integration deep within the tissue and the changes observed are not simply due to superficial MSC adherence. Although our findings provide evidence that DHT increases MSC integration, whether the cells differentiate into endothelial or cardiomyocytes was not ascertained. Based on pilot studies, treatment of MSC with DHT did not change the cell's phenotype; however, whether they change while residing within the tissue environment remains unknown. Since the studies were conducted for a maximum of $72 \mathrm{~h}$ because of limited cardiac sections viability, it is unlikely that the MSCs differentiate into ECs or cardiomyocytes. The secretion of MMPs and pro-angiogenic molecules by MSCs indicates the pro-angiogenic potential of hormone-stimulated cells. Further long-term studies are required to monitor the fate of DHT-stimulated MSC in the heart.

The mass-spectrometric results identified integrin $\beta 1$ as differentially regulated (1.8-fold) by the DHT treatment. This is concurrent with other findings which demonstrate that $\beta$-integrins are essential in MSC attachment to tissue lesions (Zwolanek et al. 2015). In addition, the DHTinduced upregulation of myosin- 9 could have a possible implication in the increased actomyosin assembly contraction. Together, these and other proteins (Table 3) participate in actin cytoskeleton rearrangement processes, data that corroborate well with our findings that MSC migration is enhanced by the DHT treatment.

The clinical relevance of our findings can only be speculated. For instance, DHT may be of therapeutic relevance in enhancing MSC integration and cardiac repair. Our findings suggest that priming of MSC may amplify the chances of their success to repair a damaged heart. However, additional in vivo studies are necessary to confirm this possibility. Although our findings suggest that DHT may promote MSC-induced cardiac repair, androgen substitution in elderly men has been shown to induce both deleterious (Budoff et al. 2017) and protective actions in older men (Ikeda et al. 2005, 2012, Liu et al. 2014). Moreover, androgens as well as ARs have been shown to induce cardiac growth, and drop in androgen levels is associated with cardiovascular disease (Dubey et al. 2002). Since MSC integration would require shortterm exposure to DHT-primed MSCs, it is feasible that its beneficial actions may override its, potential, long-term deleterious effects. However, in vivo studies are required to confirm this possibility.

Although our in vitro findings provide evidence that DHT promotes MSC integration in cardiac tissue, in vivo proof for this is still lacking. Another limitations of the study include the fact that impact of androgens, whether beneficial or deleterious, on the cardiovascular system is still unclear (Ikeda et al. 2005, 2012, Liu et al. 2014, Budoff et al. 2017). It is feasible that short-term treatment with DHT-primed MSCs may not have the same deleterious effects as in subjects taking androgen substitution; however, this possibility needs to be further investigated. MSC can evolve into many different cell types, including bone cells (Zomorodian \& Baghaban Eslaminejad 2012). Since calcification of the blood vessels leads to cardiovascular disease, the treatment with MSC should be cautiously controlled for the possible deleterious side effects and needs to be further investigated.

Finally, the rationale for using $30 \mathrm{nM}$ DHT concentrations in the present study was that the value was comparable to testosterone. Moreover, unlike testosterone, DHT is not metabolized to estradiol thereby resulting in AR-specific actions. However, it should be noted that circulating levels of DHT are 10-fold lower $(\approx 3 \mathrm{nM})$, and its affinity for $\mathrm{AR}$ is $\approx 3$-fold higher. Hence, the concentrations in the present study may not represent levels that would result in the typical androgenic response. However, our finding that NO synthesis was induced by low ( $1 \mathrm{nM})$ as well as high (30 and $100 \mathrm{nM}$ ) concentrations of DHT suggests that the effects of $30 \mathrm{nM}$ are AR mediated. Moreover, in preliminary growth studies, physiological concentrations of DHT induced MSC growth and migration, suggesting that the effects of high $30 \mathrm{nM}$ DHT were mimicked by physiological concentrations of DHT. Our contention that $30 \mathrm{nM}$ DHT induces pro-angiogenic factors and assists homing of MSCs into cardiac tissue is supported by findings from Borst and coworkers who demonstrated that supraphysiologic testosterone treatment improved recovery from cardiac ischemic reperfusion injury (Borst et al. 2010).

Although our findings suggest that culturing MSC with DHT may allow for better incorporation into cardiac tissue, in a manner independent from systemically 
elevated androgen concentrations. However, from a translational perspective, some preclinical and clinical evidence indicates that DHT may be detrimental to cardiac function. For example, Shores and coworkers reported that high circulating DHT is associated with cardiovascular disease and all-cause mortality in men (Shores et al. 2014). Rubio-Gayosso and coworkers also reported that 5-alphareductase inhibition resulted in myocardial protection after cardiac ischemic reperfusion injury and that DHT treatment increased myocardial damage resulting from ischemic reperfusion injury (Rubio-Gayosso et al. 2013). Hence, more studies using physiologic concentrations of DHT are required to further test its impact on tissue remodeling and cardiovascular repair.

In conclusion, we provide the first evidence that DHT induces growth, proliferation and migration of MSC and promotes integration of these cells into cardiac tissue in vitro. These effects are accompanied by upregulation of ARs and of key molecules known to promote tissue remodeling and angiogenesis (EMMPRIN, MMP-2, MMP-9, VEGF, angiogenin, NO). Our findings suggest that priming of MSC with DHT may functionally increase their capability to repair and regenerate cardiac tissue. However, in vivo studies using DHT-primed MSCs are necessary to confirm our in vitro observations.

\section{Declaration of interest}

The authors declare no conflict of interest that could be perceived as prejudicing the impartiality of the research reported.

\section{Funding}

The authors gratefully acknowledge the support of the Swiss-Romanian Research Programme SNSF Grant No. IZERZO_142213/1 and CNCSUEFISCDI/RSRP No. 21/2013 (Swiss PI, Dr Raghvendra K Dubey, Romanian $\mathrm{PI}, \mathrm{Dr}$ Maya Simionescu) and of the Romanian Academy.

\section{Author contribution statement}

M A P and M C M performed experiments and wrote the manuscript. A C performed Western blot analysis, C T performed Luminex assay, $\mathrm{R} C$ provide human umbilical cord samples, $\mathrm{V}$ S an $\mathrm{F}$ A performed mass spectrometry assay; M S and R K D are principal investigators who designed the experiments and were actively involved in the writing of the original and revised manuscript.

\section{Acknowledgements}

The authors thank Dr Marilena Plesu, Dr Florin lordache, Dr Adriana Georgescu and Dr Nicoleta Alexandru for their technical and logistic assistance. The authors apologize to the colleagues whose work was not cited due to space constraints. The authors gratefully acknowledge the support of the Swiss-Romanian Research Programme SNSF Grant
No. IZERZO_142213/1 and CNCS-UEFISCDI/RSRP No. 21/2013 (Swiss PI, Dr Raghvendra K Dubey, Romanian PI, Dr Maya Simionescu) and of the Romanian Academy.

\section{References}

Alexandru N, Popov D, Dragan E, Andrei E \& Georgescu A 2011 Platelet activation in hypertension associated with hypercholesterolemia: effects of irbesartan. Journal of Thrombosis and Haemostasis $\mathbf{9}$ 173-184. (https://doi.org/10.1111/j.1538-7836.2010.04122.x)

Àlvarez G, González M, Isabal S, Blanc V \& León R 2013 Method to quantify live and dead cells in multi-species oral biofilm by real-time PCR with propidium monoazide. AMB Express 3 1-8. (https://doi. org/10.1186/2191-0855-3-1)

Bird C \& Kirstein S 2009 Real-time, label-free monitoring of cellular invasion and migration with the xCELLigence system. Nature Methods 6 1-2. (https://doi.org/10.1038/NMETH.F.263)

Borst SE, Quindry JC, Yarrow JF, Conover CF \& Powers SK 2010 Testosterone administration induces protection against global myocardial ischemia. Hormone and Metabolic Research 42 122-129. (https://doi.org/10.1055/s-0029-1241843)

Boteanu RM, Suica VI, Uyy E, Ivan L, Dima SO, Popescu I, Simionescu M \& Antohe F 2016 Alarmins in chronic noncommunicable diseases: atherosclerosis, diabetes and cancer. Journal of Proteomics 153 21-29. (https://doi.org/10.1016/j. jprot.2016.11.006)

Budoff MJ, Ellenberg SS, Lewis CE, Mohler ER, Wenger NK, Bhasin S, Barrett-Connor E, Swerdloff RS, Stephens-Shields A, Cauley JA, et al. 2017 Testosterone treatment and coronary artery plaque volume in older men with low testosterone. JAMA $\mathbf{3 1 7}$ 708. (https://doi. org/10.1001/jama.2016.21043)

Cai JJ, Wen J, Jiang WH, Lin J, Hong Y \& Zhu YS 2016 Androgen actions on endothelium functions and cardiovascular diseases. Journal of Geriatric Cardiology 13 183-196. (https://doi.org/10.11909/j. issn.1671-5411.2016.02.003)

Cheung PY, Sawicki G, Wozniak M, Wang W, Radomski MW \& Schulz R 2000 Matrix metalloproteinase-2 contributes to ischemia-reperfusion injury in the heart. Circulation 101 1833-1839. (https://doi. org/10.1161/01.CIR.101.15.1833)

Corotchi MC, Popa MA, Remes A, Sima LE, Gussi I \& Plesu ML 2013 Isolation method and xeno-free culture conditions influence multipotent differentiation capacity of human Wharton's jellyderived mesenchymal stem cells. Stem Cell Research and Therapy 41 . (https://doi.org/10.1186/scrt232)

Corotchi MCC, Popa MA \& Simionescu M 2016 Testosterone stimulates proliferation and preserves stemness of human adult mesenchymal stem cells and endothelial progenitor cells. Romanian Journal of Morphology and Embryology 57 75-80. (https://doi.org/10.1093/ bioinformatics/btl627)

Davis RC, Hobbs FD \& Lip GY 2000 ABC of heart failure. History and epidemiology. BMJ 320 39-42. (https://doi.org/10.1136/ bmj.320.7226.39)

Deschamps AM \& Spinale FG 2006 Pathways of matrix metalloproteinase induction in heart failure: bioactive molecules and transcriptional regulation. Cardiovascular Research 69 666-676. (https://doi.org/10.1016/j.cardiores.2005.10.004)

Dubey RK, Oparil S, Imthurn B \& Jackson EK 2002 Sex hormones and hypertension. Cardiovascular Research 53 688-708. (https://doi. org/10.1016/S0140-6736(00)94229-6)

Ecovoiu AA, Ghionoiu IC, Ciuca AM \& Ratiu AC 2016 Genome ARTIST: a robust, high-accuracy aligner tool for mapping transposon insertions and self-insertions. Mobile DNA 7 3. (https://doi. org/10.1186/s13100-016-0061-0)

Gupta V, Bhasin S, Guo W, Singh R, Miki R, Chauhan P, Choong K, Tchkonia T, Lebrasseur NK, Flanagan JN, et al. 2008 Effects of http://jme.endocrinology-journals.org https://doi.org/10.1530/JME-17-0185
(C) 2018 Society for Endocrinology Published by Bioscientifica Ltd. Printed in Great Britain 
dihydrotestosterone on differentiation and proliferation of human mesenchymal stem cells and preadipocytes. Molecular and Cellular Endocrinology 296 32-40. (https://doi.org/10.1016/j.mce.2008.08.019)

Ikeda Y, Aihara KI, Sato T, Akaike M, Yoshizumi M, Suzaki Y, Izawa Y, Fujimura M, Hashizume S, Kato M, et al. 2005 Androgen receptor gene knockout male mice exhibit impaired cardiac growth and exacerbation of angiotensin II-induced cardiac fibrosis. Journal of Biological Chemistry 280 29661-29666. (https://doi.org/10.1074/jbc.M411694200)

Ikeda Y, Aihara KI, Yoshida S, Akaike M \& Matsumoto T 2012 Effects of androgens on cardiovascular remodeling. Journal of Endocrinology $\mathbf{2 1 4}$ 1-10. (https://doi.org/10.1530/JOE-12-0126)

Karantalis V \& Hare JM 2015 Use of mesenchymal stem cells for therapy of cardiac disease. Circulation Research 116 1413-1430. (https://doi. org/10.1161/CIRCRESAHA.116.303614)

Klein T \& Bischoff R 2011 Physiology and pathophysiology of matrix metalloproteases. Amino Acids 41 271-290. (https://doi.org/10.1007/ s00726-010-0689-x)

Liu PY, Death AK \& Handelsman DJ 2003 Androgens and cardiovascular disease. Endocrine Reviews 24 313-340. (https://doi.org/10.1210/ er.2003-0005)

Liu L, Yu Y, Hou Y, Chai J, Duan H, Chu W, Zhang H, Hu Q \& Du J 2014 Human umbilical cord mesenchymal stem cells transplantation promotes cutaneous wound healing of severe burned rats. PLOS ONE 9 e88348. (https://doi.org/10.1371/journal.pone.0088348)

Losordo DW \& Isner JM 2001 Vascular endothelial growth factorinduced angiogenesis: Crouching tiger or hidden dragon? Journal of the American College of Cardiology 37 2131-2135. (https://doi org/10.1016/S0735-1097(01)01298-0)

Mias C, Lairez O, Trouche E, Roncalli J, Calise D, Seguelas MH, Ordener C, Piercecchi-Marti MD, Auge N, Salvayre AN, et al. 2009 Mesenchymal stem cells promote matrix metalloproteinase secretion by cardiac fibroblasts and reduce cardiac ventricular fibrosis after myocardial infarction. Stem Cells 27 2734-2743. (https://doi. org/10.1002/stem.169)

Mishra PK, Givvimani S, Chavali V \& Tyagi SC 2013 Cardiac matrix: a clue for future therapy. Biochimica et Biophysica Acta: Molecular Basis of Disease 1832 2271-2276. (https://doi.org/10.1016/j. bbadis.2013.09.004)

Mohamed A, Eric H, Jean D, Dominique L, Suzanne M \& Isabelle M 2011 Extracellular matrix metalloproteinase inducer (EMMPRIN/ CD147) as a novel regulator of myogenic cell differentiation. Journal of Cellular Physiology 226 141-149. (https://doi.org/10.1002/ jcp.22315)

Müller-Ehmsen J, Krausgrill B, Burst V, Schenk K, Neisen UC, Fries JWU, Fleischmann BK, Hescheler J \& Schwinger RHG 2006 Effective engraftment but poor mid-term persistence of mononuclear and mesenchymal bone marrow cells in acute and chronic rat myocardial infarction. Journal of Molecular and Cellular Cardiology $\mathbf{4 1}$ 876-884. (https://doi.org/10.1016/j.yjmcc.2006.07.023)

Nam HS, Kwon I, Lee BH, Kim H, Kim J, An S, Lee OH, Lee PH, Kim HO, Namgoong H, et al. 2015 Effects of mesenchymal stem cell treatment on the expression of matrix metalloproteinases and angiogenesis during ischemic stroke recovery. PLOS ONE 10 e0144218. (https://doi.org/10.1371/journal.pone.0144218)

Nesselmann C, Ma N, Bieback K, Wagner W, Ho A, Konttinen YT, Zhang H, Hinescu ME \& Steinhoff G 2008 Mesenchymal stem cells and cardiac repair. Journal of Cellular and Molecular Medicine $\mathbf{1 2}$ 1795-1810. (https://doi.org/10.1111/j.1582-4934.2008.00457.x)

Papapetropoulos A, Garcia-Cardena G, Madri JA \& Sessa WC 1997 Nitric oxide production contributes to the angiogenic properties of vascular endothelial growth factor in human endothelial cells.
Journal of Clinical Investigation 100 3131-3139. (https://doi. org/10.1172/JCI119868)

Pillekamp F, Reppel M, Rubenchyk O, Pfannkuche K, Matzkies M, Bloch W, Sreeram N, Brockmeier K \& Hescheler J 2007 Force measurements of human embryonic stem cell-derived cardiomyocytes in an in vitro transplantation model. Stem Cells $\mathbf{2 5}$ 174-180. (https://doi.org/10.1634/stemcells.2006-0094)

Ray R \& Novotny N 2008 Sex steroids and stem cell function. Molecular Medicine 14 1. (https://doi.org/10.2119/2008-00004.Ray)

Ries C, Egea V, Karow M, Kolb H, Jochum M \& Neth P 2007 MMP-2, MT1-MMP, and TIMP-2 are essential for the invasive capacity of human mesenchymal stem cells: differential regulation by inflammatory cytokines. Blood 109 4055-4063. (https://doi. org/10.1182/blood-2006-10-051060)

Rubio-Gayosso I, Ramirez-Sanchez I, Ita-Islas I, Ortiz-Vilchis P, GutierrezSalmean G, Meaney A, Palma I, Olivares I, Garcia R, Meaney E, et al. 2013 Testosterone metabolites mediate its effects on myocardial damage induced by ischemia/reperfusion in male Wistar rats. Steroids 78 362-369. (https://doi.org/10.1016/j.steroids.2012.12.004)

Shores MM, Biggs ML, Arnold AM, Smith NL, Longstreth WT, Kizer JR, Hirsch CH, Cappola AR \& Matsumoto AM 2014 Testosterone, dihydrotestosterone, and incident cardiovascular disease and mortality in the cardiovascular health study. Journal of Clinical Endocrinology and Metabolism 99 2061-2068. (https://doi. org/10.1210/jc.2013-3576)

Sieveking DP, Lim P, Chow RWYY, Dunn LL, Bao S, McGrath KCYY, Heather AK, Handelsman DJ, Celermajer DS \& Ng MKCC 2010 A sex-specific role for androgens in angiogenesis. Journal of Experimental Medicine 207 345-352. (https://doi.org/10.1084/ jem.20091924)

Singh A, Singh A \& Sen D 2016 Mesenchymal stem cells in cardiac regeneration: a detailed progress report of the last 6 years (20102015). Stem Cell Research and Therapy 7 82. (https://doi.org/10.1186/ s13287-016-0341-0)

Spinale FG \& Wilbur NM 2009 Matrix metalloproteinase therapy in heart failure. Current Treatment Options in Cardiovascular Medicine 11 339-346. (https://doi.org/10.1007/s11936-009-0034-4)

Suica V-I, Uyy E, Boteanu RM, Ivan L \& Antohe F 2016 Comparative proteomic analysis of membrane microdomains isolated from two hyperlipidemic animal models. Biochimica et Biophysica Acta (BBA): Proteins and Proteomics 1864 1061-1071. (https://doi.org/10.1016/j. bbapap.2016.05.009)

Toma C, Pittenger MF, Cahill KS, Byrne BJ \& Kessler PD 2002 Human mesenchymal stem cells differentiate to a cardiomyocyte phenotype in the adult murine heart. Circulation 105 93-98. (https://doi. org/10.1161/hc0102.101442)

Uyy E, Suica VI, Boteanu RM, Manda D, Baciu AE, Badiu C \& Antohe F 2016 Endoplasmic reticulum chaperones are potential active factors in thyroid tumorigenesis. Journal of Proteome Research 15 3377-3387. (https://doi.org/10.1021/acs.jproteome.6b00567)

Wu Y, Chen L, Scott PG \& Tredget EE 2007 Mesenchymal stem cells enhance wound healing through differentiation and angiogenesis. Stem Cells 25 2648-2659. (https://doi.org/10.1634/ stemcells.2007-0226)

Zomorodian E \& Baghaban Eslaminejad M 2012 Mesenchymal stem cells as a potent cell source for bone regeneration. Stem Cells International 2012 1-9. (https://doi.org/10.1155/2012/980353)

Zwolanek D, Flicker M, Kirstätter E, Zaucke F, van Osch GJVM \& Erben RG $2015 \beta 1$ integrins mediate attachment of mesenchymal stem cells to cartilage lesions. BioResearch Open Access 4 39-53. (https://doi.org/10.1089/biores.2014.0055)

Received in final form 10 October 2017

Accepted 12 October 2017 http://jme.endocrinology-journals.org https://doi.org/10.1530/JME-17-0185 (c) 2018 Society for Endocrinology Published by Bioscientifica Ltd. Printed in Great Britain 